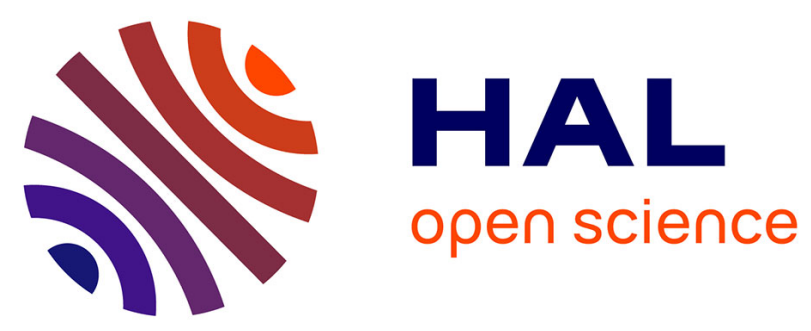

\title{
Dynamic analysis of the interaction between an abradable material and a titanium alloy
}

Guy Sutter, Sylvain Philippon, François Garcin

\section{To cite this version:}

Guy Sutter, Sylvain Philippon, François Garcin. Dynamic analysis of the interaction between an abradable material and a titanium alloy. Wear, 2006, 261 (5-6), pp.686-692. 10.1016/j.wear.2006.01.030 . hal-01223431

\section{HAL Id: hal-01223431 \\ https://hal.science/hal-01223431}

Submitted on 15 Mar 2017

HAL is a multi-disciplinary open access archive for the deposit and dissemination of scientific research documents, whether they are published or not. The documents may come from teaching and research institutions in France or abroad, or from public or private research centers.
L'archive ouverte pluridisciplinaire HAL, est destinée au dépôt et à la diffusion de documents scientifiques de niveau recherche, publiés ou non, émanant des établissements d'enseignement et de recherche français ou étrangers, des laboratoires publics ou privés. 


\title{
Dynamic analysis of the interaction between an abradable material and a titanium alloy
}

\author{
G. Sutter ${ }^{\mathrm{a}}$, S. Philippon ${ }^{\mathrm{b}}$, F. Garcin ${ }^{\mathrm{c}}$ \\ a LPMM, UMR CNRS no. 7554, ISGMP, Université Paul Verlaine de Metz, Ile du Saulcy, 57045 Metz Cedex 1, France \\ ${ }^{\mathrm{b}}$ LPMM, Ecole Nationale d'Ingénieurs de Metz, Ile du Saulcy, 57045 Metz Cedex 1, France \\ c SNECMA, site de Villaroche, 77550 Moissy-Cramayel, France
}

\begin{abstract}
The purpose of the present paper is to study interaction phenomena between an abradable material (M601) and a titanium alloy (TA6V). This interaction which can occur in an aircraft engine when the rotating blade tips rub on the compressor casing, is analysed on an experimental laboratory set-up. Only orthogonal cutting conditions are considered in this preliminary study to monitor the load evolution with velocity. The experimental results obtained for a range of velocities $10<V<107 \mathrm{~m} / \mathrm{s}$ and for a range interaction depth $0.05<t_{1}<0.5 \mathrm{~mm}$ are presented. After analysis of measurements, the mean interaction force increases proportionally to the interaction depth increment. The effects of the contact geometry on the loads, especially the radius of the edge, are investigated. The increase of the radius value for a given interaction depth increases the load value.

This work provides new basic data for behaviour laws introduced in numerical models simulating the interaction between the blade tip and the compressor casing in turbine engine applications. Original high-speed photographs recorded in real time during the process illustrate the chip separation by brittle manner. A temperature field in the abradable material will be able to be obtained for only a low speed of $5 \mathrm{~m} / \mathrm{s}$.
\end{abstract}

Keywords: Abradable material; Blade/casing interaction; High-speed experimental device; Force measurement

\section{Introduction}

The optimisation of compressor engines is of prime importance for the improvement of aircraft performances. The increasing compressors efficiency and therefore the reduced fuel consumption can be obtained by minimizing the clearance between compressor casing and the rotating blade tip [1,2]. The adopted technical solution consists in the use of the blade tip, as a cutting tool, to scrape the casing. This method is widespread in other turbine-engine applications such as labyrinth seals in bearings [3] or the turbocharger of diesel engines [4].

Therefore the compressor casing is covered with abradable material. This coating, composed of metal phase and selflubricating non-metal phase with high porosity, offers a good balance between abradability and erosion resistance [5-7]. In addition, the smooth surface obtained after the interaction pro- cess, favourable to aerodynamics properties, must be generated without damage to the blade tip.

Unfortunately, turbine rotor misalignment, start-ups, stops, vibrations, thermal and centrifugal effects on the rotating blades create undesirable interaction. The casing geometry is then modified, increasing the clearance and damaging the blades. Particles of abradable material of the coating are transferred onto the blades increasing the mass and are ingested by the engine [1]. The necessity for the aircraft engineering to understand the interaction behaviour allows to avoid premature turbine wear or failure, and then to increase the useful lives of engines.

The wear mechanisms occurring in abradable seals of gas turbines have been identified by an investigation of worn components, see Borel et al. [8]. The main interaction mechanisms are cutting, deformation, adhesive transfer and melting. Three other mechanisms occur without contact: erosion, corrosion and heating. In these last cases, roughness, surface chemistry and color have been changed. The deformation process creates a striated surface and compacts coating leading to more future violent interactions. The adhesive transfer corresponds to the 
transfer of material from the coating onto the blade or reciprocally and is often associated with the deformation mechanism. This material transfer may form an alloy having a lower melting point than the original constituents. The melting of these alloys produces a hard layer during the following rubbing interaction and can seriously damage the blade. Thus, deformation, adhesive transfer and melting are not favourable and must be avoided. When the cutting interaction is observed, a new smooth surface with a shiny appearance is generated and the blade tip is not damaged.

Extensive research about erosion resistance and abradability has been carried out [5-7]. The abradability tests were carried out on a rub test machine [7] for small sliding velocity $V=0.377 \mathrm{~m} / \mathrm{s}$ and for loads varying from 40 up to $100 \mathrm{~N}$. The results obtained show the abradability decrease with the increase of hardness for a given kind of coating (the abradable specimens tested were M307, M310, M313 and M601). But for similar hardness of different kinds of coating, abradability is very different. So, the choice of the coating cannot be confirmed only with hardness. The erosion wear behaviour was investigated by a sand erosion machine for impact velocity in a range from 30 to $80 \mathrm{~m} / \mathrm{s}$ and for an impact angle in a range from $30^{\circ}$ to $90^{\circ}$ [6]. The erosion rate is related to the characteristics of the abradable material such as composition, microstructure and hardness, but it is not related to the thickness of the coating. At $30^{\circ}$ impact angle, micro-cutting plowing and tunneling of the non-metal phase was observed.

But the frequently used test device is the Sulzer Metco rig. It consists of a rotor on which a blade is mounted while the abradable material specimen is fixed on a dynamometer. The temperature measurements during the process can be obtained by a thermocouple inserted in the specimen [5] or a thermocouple array fixed on the back surface of the blade [9] or by optical pyrometers [9-11]. The effects on the interaction mechanism of the blade tip incursion rate (from 2 to $2000 \mu \mathrm{m} / \mathrm{s}$ ), incursion depth (a few tenths of millimeter) blade tip velocity (from 100 to $450 \mathrm{~m} / \mathrm{s}$ ), coating temperature, coating properties, rubbing duration, blade material and shape can be investigated [2]. Note that generally, the edge of the blade tip is at right angle with motion direction and parallel to the abradable specimen [11]. This rig has been used to analyse the transfer of coating onto the blade for a blade velocity in a range from 200 to $400 \mathrm{~m} / \mathrm{s}$ and for incursion velocity in a range from 10 to $500 \mu \mathrm{m} / \mathrm{s}$ [5]. The obtained results show that if the blade incursion is set deep into the abradable coating, the material transfer is lessened. In the same way, an increase of the blade velocity decreases the coating material transfer onto the blade. The normal and transverse forces due to the interaction between different coatings sprayed on the blade tip and seal material $(80 \% \mathrm{Ni}-20 \% \mathrm{Cr})$ were measured with the same rub device where the blade tip velocity was maintained constant at $100 \mathrm{~m} / \mathrm{s}$ [11]. For incursion rates of 0.0127 and $0.0254 \mathrm{~mm} / \mathrm{s}$, with an incursion depth of $0.5 \mathrm{~mm}$, the normal and transverse force varied approximately from 200 to 520 and 50 to $150 \mathrm{~N}$, respectively. In addition the temperature measurements of the abradable seal and the blade were obtained during the interaction process by two optical pyrometers [11]. In these tests, the transverse force and temperature, which varied from 500 to $1170^{\circ} \mathrm{C}$, seemed to be reasonably well correlated. This was confirmed as this temperature was reached due to the frictional energy which is directly proportional to the transverse force. To investigate temperature at an incursion rate of $0.75 \mathrm{~mm} / \mathrm{s}$, two optical pyrometers were used during the interaction process of four titanium blades rubbing at $152.4 \mathrm{~m} / \mathrm{s}$ against two kinds of sealling material ( $\mathrm{NiCrAl}-$ silicate and $\mathrm{AlSi}$ ) [10].

In the case of titanium blade and $\mathrm{NiCrAl}-$ silicate seal interaction, the measured temperatures were 1259 and $881^{\circ} \mathrm{C}$, respectively. These temperatures were lower $\left(601\right.$ and $798^{\circ} \mathrm{C}$, respectively) when the titanium blade was rubbed against the AlSi seal.

A different configuration was used to determine the interaction temperature with the following parameters: incursion rate from 0.0025 to $0.25 \mathrm{~m} / \mathrm{s}$ and blade tip velocity from 152 to $213 \mathrm{~m} / \mathrm{s}$ [9]. In these tests, the abradable material (hastelloy $\times$ feltmetal fibermetal) was applied on the rim of a rotating disk and the instrumented blade was mounted on the dynamometer. The blades made of titanium or Incoloy 901 were skewed at $45^{\circ}$ from the plane of the disk rotation to reproduce rub geometry similar to the blade tip of the compressor. The maximal temperature reached was about $1300{ }^{\circ} \mathrm{C}$, although a quick quenching follows this increase. The incursion rate was found to be the most important independent variable while the blade tip velocity and the blade thickness showed moderate influence.

To sum up, the coating/blade interaction and results are important in the engine efficiency. This complex process is influenced by many parameters and gets complicated with the need for minimal clearances combined with the high speed. The extreme friction conditions between abradable coating and titanium blade can become identified with the domain of high-speed machining. In this work, an experimental approach of the interaction mechanism is developed by means of an original device used for the high-speed machining study [12]. The particular behaviour of the abradable material during the cut (weak cutting force), required the development of a sensitive load sensor. Two different solutions were compared in the presented results to define the most adapted to the interaction conditions. The influence of the interaction depth is analysed for a range of interaction speed reaching $110 \mathrm{~m} / \mathrm{s}$. Directly connected to manufacture, the edge radius of the blade tip is studied for two values corresponding to rectification and to taking the burrs off. To complete this work, high-speed photographs were taken in real time during the interaction process. A temperature field in the abradable material will be able to be obtained for only a low speed of $5 \mathrm{~m} / \mathrm{s}$.

\section{Experimental device}

The interaction between a compressor blade and the casing is analysed by means of an experimental device using a pneumatic gun. This propulsion device has been designed to obtain high-speed orthogonal cutting behaviours [12]. The maximal speed obtained with this device can reach $120 \mathrm{~m} / \mathrm{s}$. Although the velocities reached at the compressor blade extremities are about $500 \mathrm{~m} / \mathrm{s}$ for the first compressor stage. This paper presents the work of a pre-study allowing the validation of the measurement 


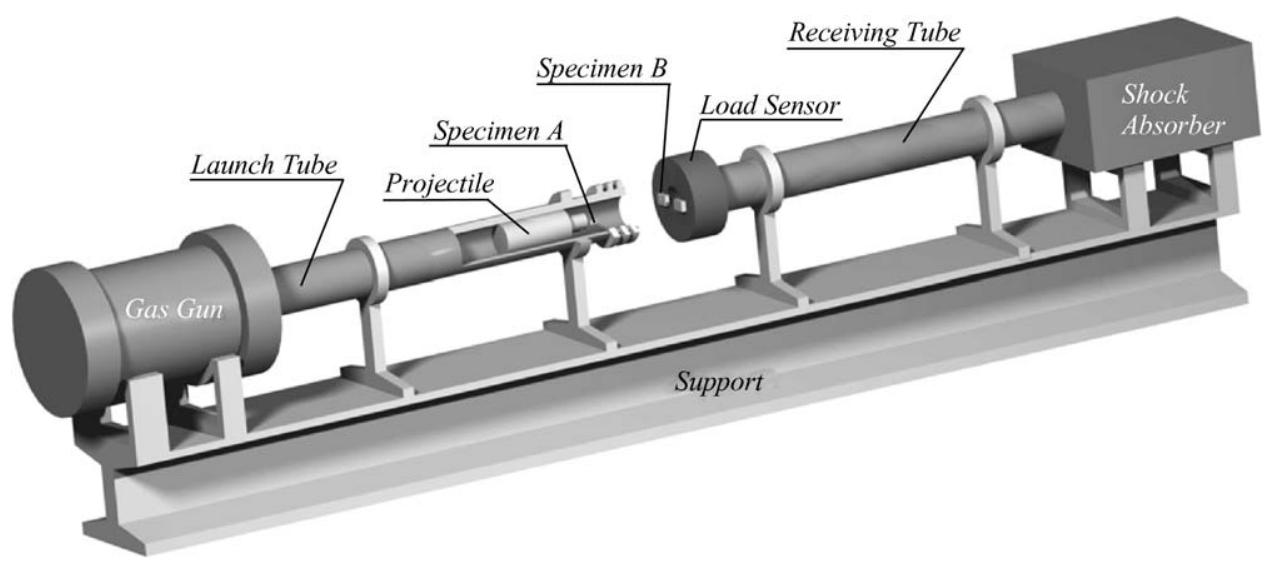

Fig. 1. Experimental device with high-speed launcher.

chains at high speeds. Of course the analysis perspectives are to expand the explored velocities range in order to reach the real velocities. This experimental device is mainly composed (see Fig. 1) of a pneumatic air gun using the compressed gas expansion to launch a projectile. This projectile supports workpiece A which is covered with abradable material, and is guided along a launch tube during its acceleration step. The accurate tolerances of the tube geometry and the good surface condition allow to obtain an optimal precision of the projectile trajectory and ensure the workpiece position during the interaction with specimen B. Projectiles with different densities are used in terms of the velocity ranges and forces encountered in order to ensure quasi-stationary conditions. Note that the kinetic energy decrease during the interaction corresponds to a maximal relative velocity variation of $4 \%$. The high speed (about $120 \mathrm{~m} / \mathrm{s}$ ) is obtained with a projectile made of nylon.

A second tube (receiving tube) allows to guide the projectile towards a shock absorber designed to receive the workpiece without damage for post-experiment analysis. The sideextremities of the parallelepiped workpiece A are covered with abradable material whose chemical composition is presented in Table 1. This type of material is only characterized by the Rockwell hardness (HR15y) for which the value is 51 [7]. Specimen $B$ made of a titanium alloy (Table 2) simulates the behaviour of the engine rotor blades. They are symmetrically fixed on a load sensor. The interaction depth between the abradable material and specimen $\mathrm{B}$ is modulated using the combination of the distance separating specimen B and the length of workpiece A. A groove is machined into the support (Fig. 2) before the abradable material deposit in order to minimize its unsticking during the

Table 1

Chemical composition of abradable material M601

\begin{tabular}{|c|c|c|c|c|c|c|}
\hline & \multicolumn{6}{|c|}{ Element $(\%)$} \\
\hline & $\mathrm{Si}$ & $\mathrm{Fe}$ & $\mathrm{C}$ & Impurities & $\mathrm{Al}$ & Polyester \\
\hline \multicolumn{7}{|c|}{ Aluminum-silicon alloy and polyester } \\
\hline Min. & 6.50 & - & - & - & 51 & The rest \\
\hline Max. & 8.50 & 0.5 & 0.2 & 0.35 & 55 & The rest \\
\hline
\end{tabular}

Table 2

Chemical composition and mean mechanical properties of titanium alloy TA6V

\begin{tabular}{|c|c|c|c|c|c|c|c|}
\hline & \multicolumn{7}{|c|}{ Element $(\%)$} \\
\hline & $\mathrm{Ti}$ & $\mathrm{Al}$ & $\mathrm{V}$ & $\mathrm{C}$ & $\mathrm{Fe}$ & $\mathrm{O}_{2}$ & $\mathrm{~N}_{2}$ \\
\hline Min. & Base & 5.50 & 3.50 & & & & \\
\hline Max. & Base & 6.75 & 4.50 & 0.08 & 0.30 & 0.20 & 0.0 \\
\hline \multicolumn{8}{|c|}{ Material properties (annealing temperature at $700^{\circ} \mathrm{C}$ for $2 \mathrm{~h}$ ) } \\
\hline \multicolumn{7}{|c|}{ Hardness (Brinell) } & 335 \\
\hline \multicolumn{7}{|c|}{ Yield stress (MPa) } & 930 \\
\hline \multicolumn{7}{|c|}{ Ultimate tensile strength (MPa) } & 1000 \\
\hline \multicolumn{7}{|c|}{ Modulus of elasticity (GPa) } & 108 \\
\hline \multicolumn{7}{|c|}{ Density $\left(\mathrm{kg} / \mathrm{m}^{3}\right)$} & 4450 \\
\hline
\end{tabular}

interaction. Fig. 2 presents a specimen A with only one extremity covered with abradable material to show the preparation before the material deposit.

A set of photo-diodes placed at the launching tube exit and coupled with time counters establishes the record of the velocity.

The load sensor, detailed in Fig. 3, supporting specimen B is equipped with strain gauges in order to measure the axial forces generated by the contact between the abradable and the titanium alloy. This sensor has been calibrated statically and dynamically by means of impacts at low speed. A double validation of the strains measured by this sensor has been performed. Firstly,

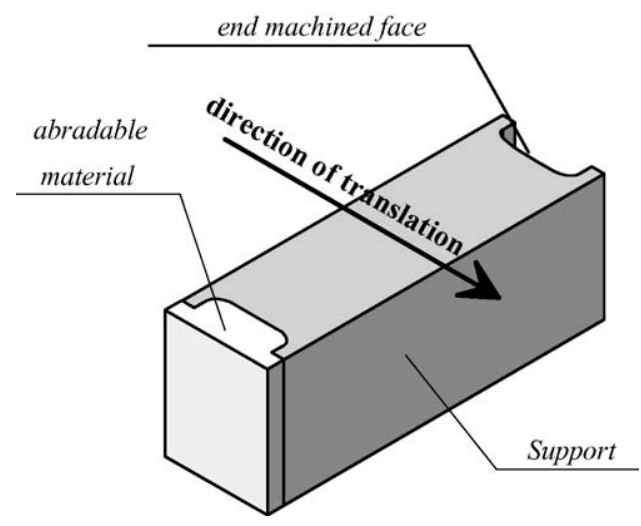

Fig. 2. Specimen A. 


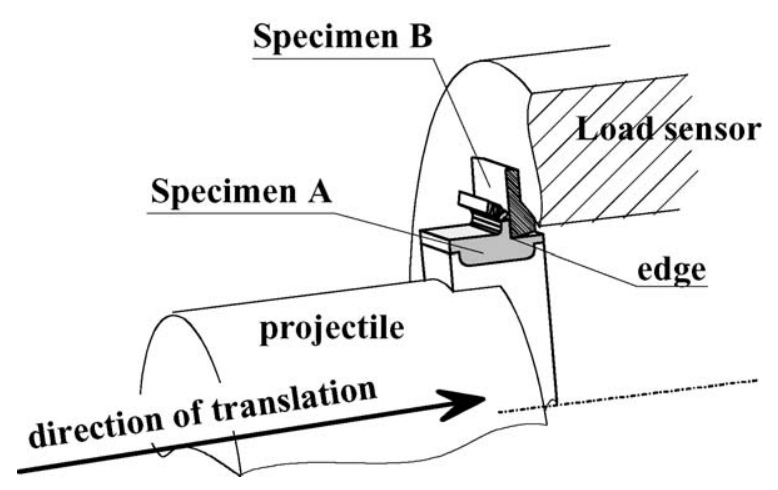

Fig. 3. Detail of the different components used to simulate high-speed interaction.

numerical analysis by finite elements confirmed the calibration. Secondly, a KISTLER piezoelectric strain sensor (piezoelectric sensor for indirect measurement) was implanted in this support to check the set sensitivity. The evolution of sensors exit signals presented in Fig. 4 confirms important sensitivity of both load sensors and in addition their linearity in terms of load.

Different tests were carried out at high interaction velocities using a first load sensor equipped with strain gauges and a second with a piezoelectric sensor. The signals, obtained respectively by the strain gauges and the piezoelectric sensor, are presented in Figs. 5 and 6. Although the sensitivity of these two sensors remains close, the frequency of the piezoelectric sensor due to the mass disrupts the measurement by superimposition of a damped oscillation. These disturbances are all the more intense as the interaction speed is high.

In spite of damped oscillations visible on the recording obtained with the piezoelectric sensor, the mean values of the two signals correspond to the same interaction forces. These tests confirmed the calibration of the sensor using deformation gauges. The results presented below are obtained with the second sensor.

To analyse the behaviour of the two materials during the process, a high-speed camera is located near the zone of interaction. Due to the high velocities of the interaction, the phenomenon duration time to be filmed requires very short exposure time (of the order of a few microseconds). Significant luminous intensity is also needed, which is ensured by two flashes of high power. This video recording requires a perfect synchronization of the trigger mechanism with the photographic recording system.

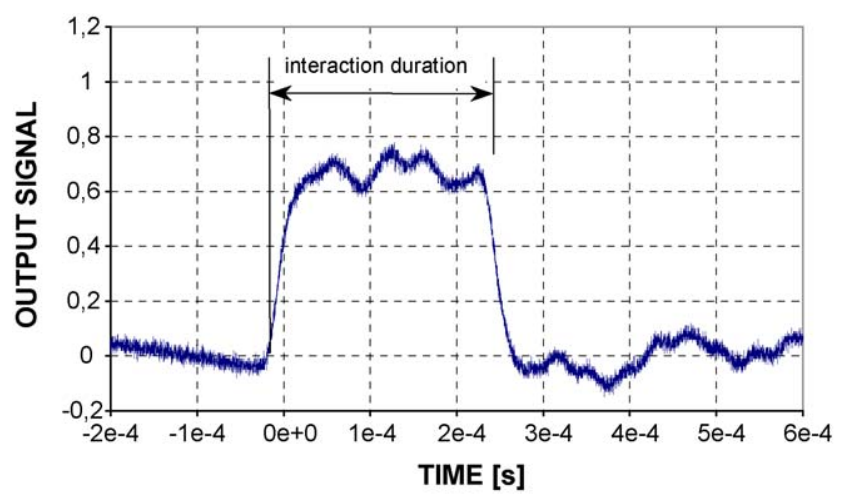

Fig. 5. Typical signal obtained with strain gauges located on the load sensor. Depth of interaction $t_{1}=0.10 \mathrm{~mm}$, interaction velocity $V=44 \mathrm{~m} / \mathrm{s}$, edge sharpness $r=0.001 \mathrm{~mm}$.

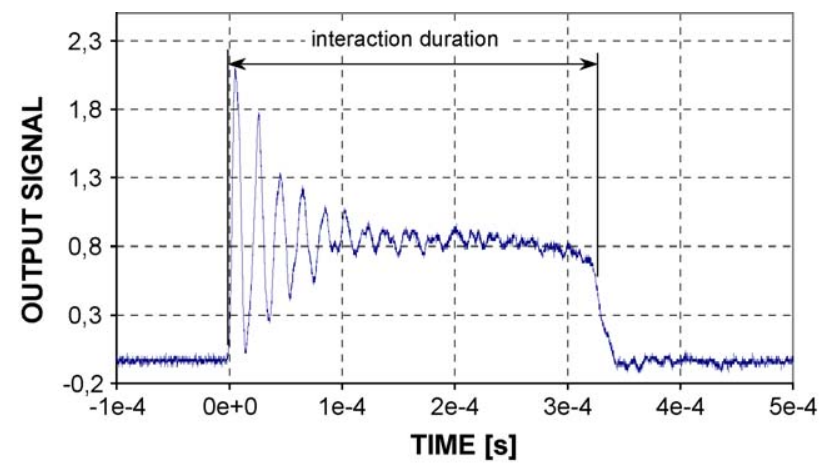

Fig. 6. Typical signal obtained with KISTLER piezoelectric sensor located in the load sensor. Depth of interaction $t_{1}=0.10 \mathrm{~mm}$, interaction velocity $V=37.2 \mathrm{~m} / \mathrm{s}$, edge sharpness $r=0.001 \mathrm{~mm}$.

\section{Results and discussion}

The first results presented in this paper are only a simplified approach of the real phenomena. Indeed an orthogonal interaction is simulated with our device in order to understand the intricate mechanisms which are taking place in the blades/casing interface. The edge of the moving specimen B is perpendicular to the translation direction. It is possible to establish a similarity with an orthogonal cutting process (Fig. 7). Furthermore the inclined plane of the profile of specimen $\mathrm{B}$ is $6^{\circ}$ comparable to a clearance angle. Various edge sharpness, noted $r$ in Fig. 7, are imposed to specimen B to study the influence of the finishing process during the compressor blade manufacture. The tests pre-
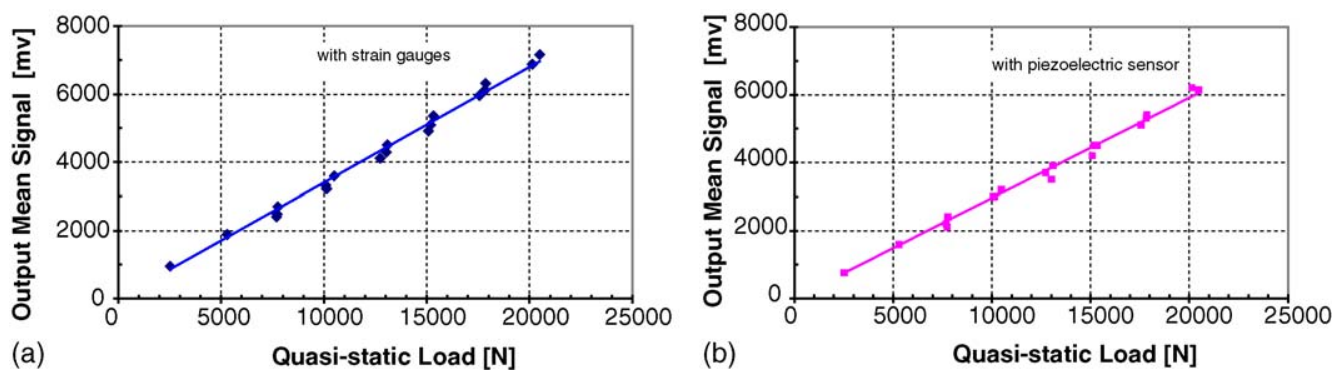

Fig. 4. Responses of load sensors with strain gauges (a) and KISTLER piezoelectric sensor (b) in terms of quasi-static load. 


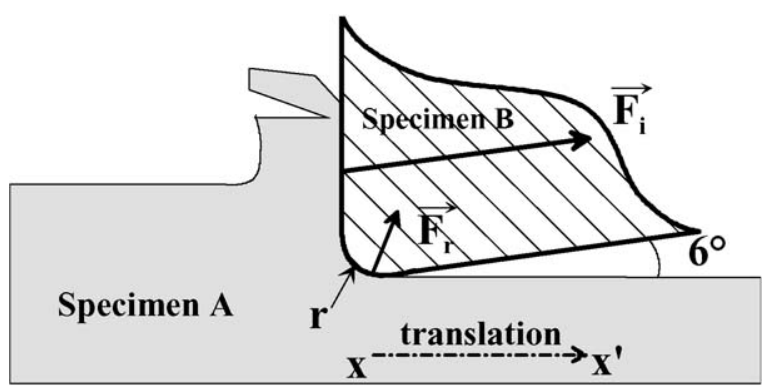

Fig. 7. Detail of the contact localized under the edge of specimen B.

sented here have been performed with two edge radii $r=0.001$ and $0.03 \mathrm{~mm}$.

Fig. 8 presents the evolution of the measured forces $F$, created during the interaction between the two materials $\mathrm{M}_{\mathrm{A}}$ (abradable material) and $\mathrm{M}_{\mathrm{B}}$ (titanium alloy) for a translation velocity reaching $107 \mathrm{~m} / \mathrm{s}$ and an edge radius $r=0.001 \mathrm{~mm}$. An increase in forces is observed with the increase of the translation velocity. This sensitivity is at its highest when the interaction depth is high.

The intensity of the force does not seem to be linearly following the interaction depth $t_{1}$. Indeed, for a velocity $V=50 \mathrm{~m} / \mathrm{s}$ and $t_{1}=0.05 \mathrm{~mm}$, the average force $F$ is $65 \mathrm{~N}$. At the same velocity, an interaction depth $t_{1}=0.1 \mathrm{~mm}$ corresponds to a force of $112 \mathrm{~N}$ and for $t_{1}=0.5 \mathrm{~mm}, F=405 \mathrm{~N}$. However we have to assume that the contact localized under the edge of specimen $\mathrm{B}$ generates a residual force. This residual force generated by friction, exists even with an interaction depth $t_{1}=0$. This phenomenon has been experimentally verified for a decrease of the interaction depth close to 0 , the interaction force reaches a minimum value different from 0 . This residual force, noted $F_{\mathrm{r}}$, depends on the interaction speed but is mainly influenced by the value of the edge radius. Following this analysis, an edge radius of $0.001 \mathrm{~mm}$ combined with a minimal depth $t_{1}$ leads to a force $F_{\mathrm{r}}=50 \mathrm{~N}$ for the lower velocities and $65 \mathrm{~N}$ for higher velocities.

For some edge radius and some interaction speed, the measured force $F$ can be also defined by the amount of a variable force $F_{\mathrm{i}}$ and a constant force $F_{\mathrm{r}}$ (see Fig. 7). This variable inter-

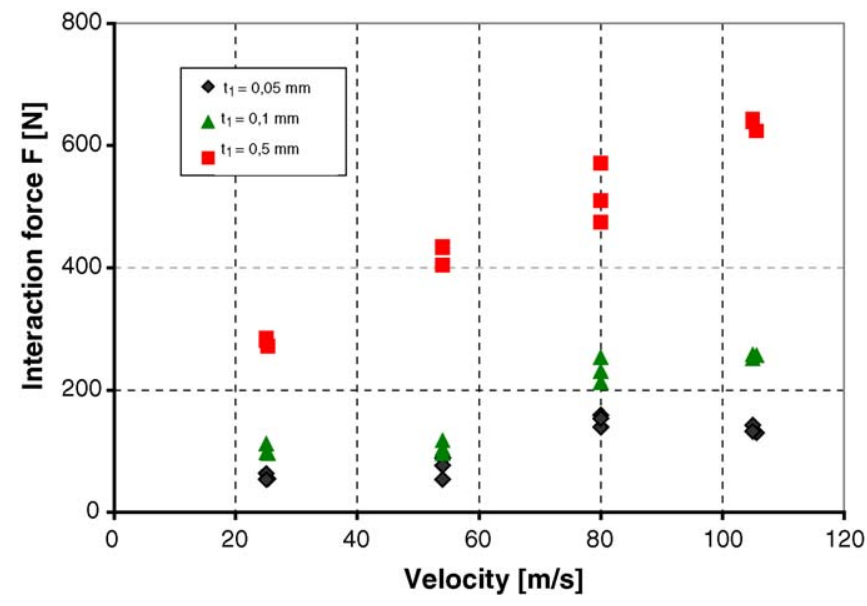

Fig. 8. Interaction forces as function of translation velocity. Depth of interaction $t_{1}=0.05,0.1,0.5 \mathrm{~mm}$, edge radius $r=0.001 \mathrm{~mm}$.

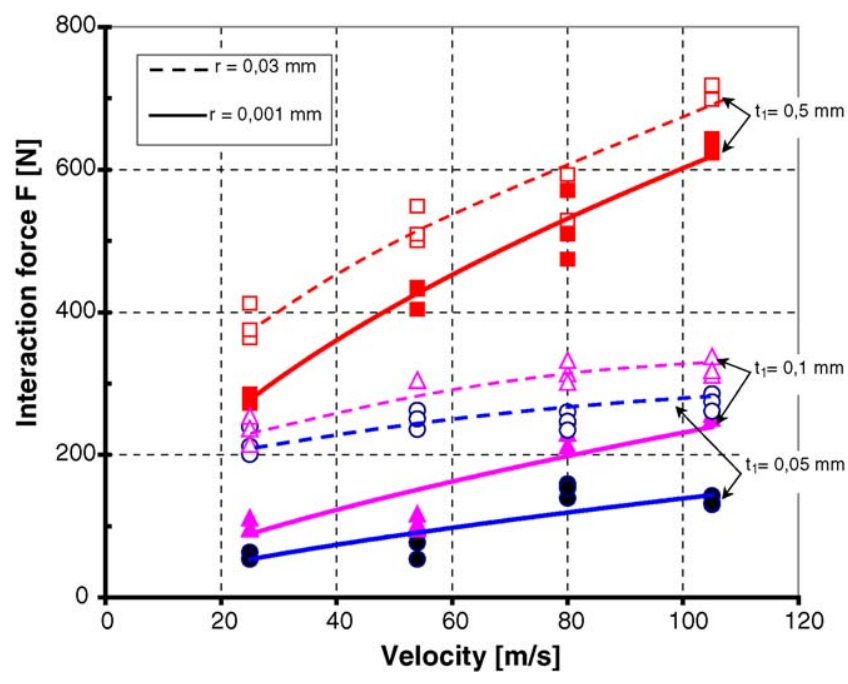

Fig. 9. Interaction forces for two edge radii: $r=0.001$ and $0.03 \mathrm{~mm}$.

action force can be represented by the following equation:

$F_{\mathrm{i}}=F-F_{\mathrm{r}}$

Thus for $t_{1}=0.1 \mathrm{~mm}$, the interaction force $F_{\mathrm{i}}=112-50=62 \mathrm{~N}$ and for $t_{1}=0.5 \mathrm{~mm}, F_{\mathrm{i}}=355 \mathrm{~N}$. These forces $F_{\mathrm{i}}$ are proportional to the interaction depth.

In order to study the influence of the edge radius on the evolution of the forces, the previous tests are performed with a different value of $r=0.03 \mathrm{~mm}$. The increase of the radius leads to the increase of interaction forces as seen in Fig. 9. The increasing force with respect to the edge radius is due mainly to the increase of the friction forces at the interface between two materials. Indeed a higher radius increases the friction area which leads to decrease the contact pressure. Consequently the friction coefficient increases as well as the residual force $F_{\mathrm{r}}$.

The interaction area is detailed in Fig. 10 in static position and Fig. 11 presents the video recording during the interaction process. As expected in the jet engine, the interaction between the titanium alloy and abradable material does not generate con-

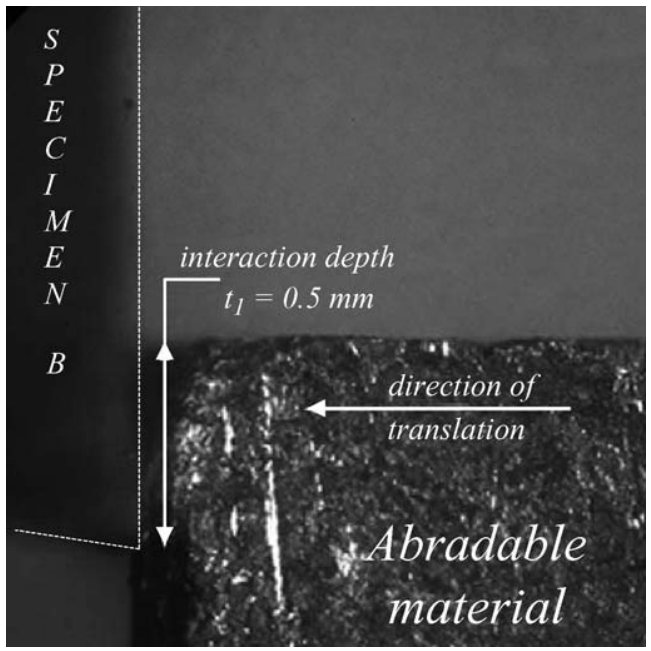

Fig. 10. Photograph of the interaction area in static position. The abradable material (specimen A) is in position near the titanium alloy (specimen B). 


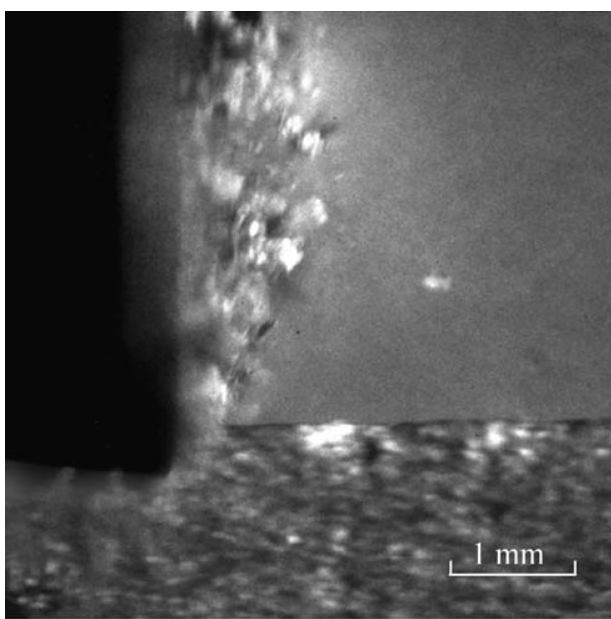

(a)

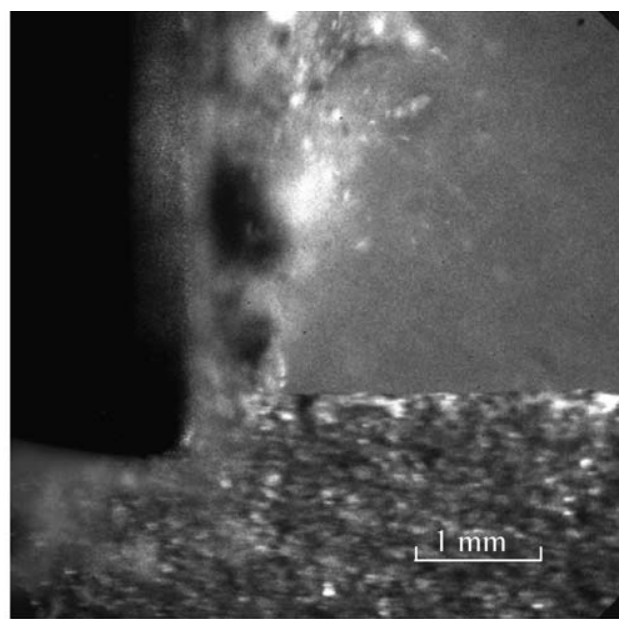

(b)

Fig. 11. Real time photographs of interaction. (a) Interaction speed $V=46 \mathrm{~m} / \mathrm{s}$; depth $t_{1}=0.5 \mathrm{~mm}$. (b) Interaction speed $V=56 \mathrm{~m} / \mathrm{s}$; depth $t_{1}=0.5 \mathrm{~mm}$.

tinuous chips or too big particles. These pictures confirm that the interaction produces fine particles obtained by brittle manner already observed by Borel et al. [8].

An infrared video camera has been used to record the temperature gradient during the interaction. Because of the low dynamic of this video camera it has not been possible to record at high velocity. On the other hand we have used the high-speed numerical camera as a pyrometer to detect the temperature field near the interaction zone. This original technique was developed by Sutter et al. [13] and Ranc et al. [14] to record the temperature during high-speed machining. Unfortunately, the evolution of the temperature during the interaction is not large enough to be measured by this set-up. In spite of the very good resolution of this measurement device, the hot zones may be too localized. In addition the emission of particles at high speeds may obstruct the camera field of vision.

Fig. 12 presents the temperatures reached with a velocity of about $5 \mathrm{~m} / \mathrm{s}$. The low increase of the observed temperature predicts a limited influence of the temperature during the interaction under these conditions.

The reduced interaction velocity imposed by limited frame rate $(200 \mathrm{~Hz})$ of the infrared camera can explain the low measured temperature. Rapid increasing temperatures with the velocity allow to reach similar high temperatures as those previously mentioned $[10,11]$. Moreover, in the previous works,

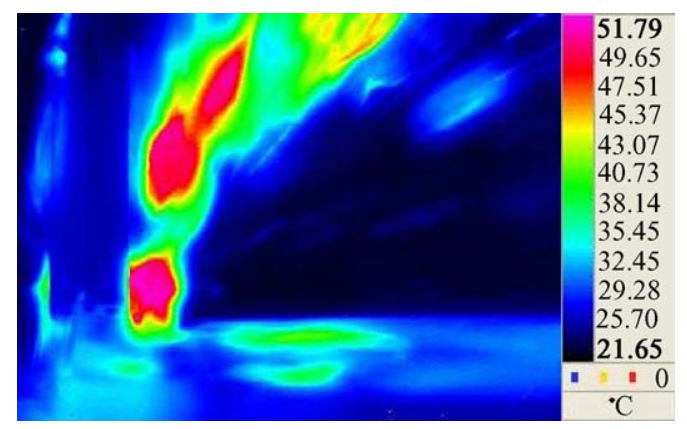

Fig. 12. Temperature field during the interaction abradable/titanium at a speed of $5 \mathrm{~m} / \mathrm{s}$. the experiments are carried out on a rub test machine where the interaction process is repeated several times during the test. Consequently these repetitive contacts extend the thermal affected zone by conduction. The heated area is also more detectable.

\section{Conclusion}

To optimise the performance of aircraft engines, contact between blades and covers of casing must be analysed, especially at very high speed. Furthermore, numerical simulations require experimental data to validate the modelling. This work presents an experimental device able to attempt at first speeds of interaction of $107 \mathrm{~m} / \mathrm{s}$. Orthogonal conditions of interaction are used to measure generated forces. The measurement forces are proportional to the interaction depth and are superimposed on forces due to the friction near the interface of two materials. The increase of the interaction speed imposes a force increase more marked for the high interaction depths. The sharp edge of one interaction material influences essentially the intensity of the friction component of the force. A blunted edge tends to increase the interaction forces. These first results show the influence of the blade tip geometry on the applied interaction load and must be considered to design the blade.

High-speed video recordings allowed to define the nature of shavings produced at high velocities. They are mainly consisted in fine particles. The measurement of the temperature fields during interaction is limited to speeds around $5 \mathrm{~m} / \mathrm{s}$. For this speed range the rise of temperature does not seem significant.

\section{Acknowledgment}

The authors are grateful for the support provided by SNECMA.

\section{References}

[1] Abradable seal with improved properties, Sealing Technol. (8) (2002) 14-15. 
[2] M. Dorfman, U. Erning, J. Mallon, Gas turbines use abradable coatings for clearance-control seals, Sealing Technol. (1) (2002) 14-15.

[3] Z. Mutasim, L. Hsu, E. Wong, Evaluation of plasma sprayed abradable coatings, Surf. Coating Technol. 54/55 (1992) 39-44.

[4] T. Sato, T. Morotomi, Development of the new TD27Eti engine for recreational vehicles, JSAE Rev. 17 (1996) 417-422.

[5] M. Bounazef, S. Guessasma, B. Ait Saadi, The wear, deterioration and transformation phenomena of abradable coating BN-SiAl-bounding organic element, caused by the friction between the blades and the turbine casing, Mater. Lett. 58 (27/28) (2004) 3375-3380.

[6] Y. Maozhong, H. Baiyun, H. Jiawen, Erosion wear behaviour and model of abradable seal coating, Wear 252 (1/2) (2002) 9-15.

[7] Y. Maozhong, H. Jiawen, H. Baiyun, Z. Huijiu, Friction and wear behaviour and abradability of abradable seal coating, Wear 231 (1) (1999) 47-53.

[8] M.O. Borel, A.R. Nicoll, H.W. Schläpfer, R.K. Schmid, The wear mechanisms occurring in abradable seals of gas turbines, Surf. Coating Technol. 39/40 (1989) 117-126.
[9] W.F. Laverty, Rub energetic of compressor blade tip seals, Wear 75 (1) (1982) $1-20$.

[10] H. Wang, Criteria for analysis of abradable coatings, Surf. Coat. Technol. $79(1-3)(1996) 71-75$.

[11] A.F. Emery, J. Wolak, S. Etemad, S.R. Choi, An experimental investigation of temperatures due to rubbing at the blade-seal interface in an aircraft compressor, Wear 91 (2) (1983) 117-130.

[12] G. Sutter, A. Molinari, L. Faure, J.R. Klepaczko, D. Dudzinski, An experimental study of high-speed orthogonal cutting, J. Manuf. Sci. Eng. 120 (1998) 169-172.

[13] G. Sutter, L. Faure, A. Molinari, N. Ranc, V. Pina, An experimental technique for the measurement of temperature fields for the orthogonal cutting in high speed machining, ASME Int. J. Mach. Tools Manuf. 43 (2003) 671-678.

[14] Ranc, V. Pina, G. Sutter, S. Philippon, Temperature measurement by visible pyrometry—orthogonal cutting application, J. Heat Transfer ASME 126 (2004) 931-936. 